\title{
PELOS CAMINHOS DA UNIVERSITARIZAÇ̃̃O: REFLEXÕES A PARTIR DA MASTERIZAÇÃO DOS IUFM' FRANCESES
}

Flavia Medeiros Sarti*

RESUMO: O artigo problematiza as vinculações comumente estabelecidas entre a universitarização da formação docente e o movimento de profissionalização e, portanto, de valorização do magistério. O tema é discutido a partir dos resultados de uma pesquisa sobre o lugar que os professores da Educação Básica assumem no campo da formação docente, hoje, internacionalmente, caracterizado pela universitarização do magistério. Tomando o contexto francês como referência, a investigação focalizou o espaço que os professores formadores, tradicionalmente atuantes nos estágios curriculares docentes e no interior dos Instituts Universitaires de Formation de Maîtres - IUFM, ocuparam na formação para o magistério, quando, naquele país, tal formação foi elevada ao nível mestrado e incorporada à estrutura universitária. Os desafios então enfrentados por esses formadores sugerem que a universitarização, sob certas condições, pode fragilizar significativamente a dimensão socioprofissional da formação inicial docente, comprometendo a legitimidade dessa modalidade de formação no campo educativo e produzindo um cenário paradoxalmente próximo à antiuniversitarização.

Palavras-chave: Formação de Professores; Profissionalização do Magistério; Universitarização; Formadores de Professores.

\footnotetext{
* Doutora em Educação pela Universidade de São Paulo (USP); Professora do Departamento de Educação da Universidade Estadual Paulista (UNESP), campus Rio Claro. E-mail: fmsarti@rc.unesp.br
} 


\section{GOING ALONG WITH THE UNIVERSITARIZATION: REFLECTIONS FROM THE MASTERIZATION OF THE FRENCH IUFM}

ABSTRACT: The article problematizes the bindings generally established between the universitarization of teachers' education and the movement of professionalization and, therefore, the valorization of teaching. The discussion is based on results of a research about teachers place at the current field of teachers' education, internationally characterized by the universitarization of teaching. Taking the French context as a reference, the investigation focused on the role of teachers' educators - traditionally active in the teaching curricular stages and at the IUFM - in the teachers' education, when it was reclassified in France to the master level and included in the university. The challenges faced by these educators suggest that the universitarization may, under certain conditions, significantly weaken the socio-professional dimension of initial education of teachers, compromising the legitimacy of this modality of teachers' education in the educational field and producing a context paradoxically close to the anti-universitarization.

Keywords: Teachers' Education, Teaching Professionalization, Universitarization, Teachers, Educators.

"Antes, nós estávamos no mesmo barco da formação, mas, hoje, não estamos mais no mesmo barco. [...] Nós caminhamos de modo paralelo, sem que nossos caminhos jamais se encontrem."

(Marianne, professora formadora, sobre suas relações com os formadores do IUFM)

Onde, como e por quem os professores da educação básica devem ser formados? Disputas em torno dessa questão animam o jogo da formação docente, em que diferentes grupos, informados por seus habitus e munidos de seus capitais, disputam o poder sobre os mecanismos que constituem esse campo (pensado ao modo de Bourdieu, 1983). Tais agentes buscam, na dinamicidade das trocas simbólicas, impor o valor de seus produtos e sua autoridade como produtores legítimos.

Os professores da escola mantêm, tradicionalmente, posição pouco privilegiada nesse espaço concorrencial, visto que os capitais que geralmente possuem - diplomas, saberes, círculo de relações etc. - alcançam baixo valor simbólico, não lhes permitindo ocupar um lugar próprio (DE CERTEAU, 1994), de querer e de poder nesse jogo. Grupos que detêm capitais considerados mais valiosos no campo costumam definir o lugar a partir do qual os professores podem jogar. 
Entretanto, o movimento de profissionalização do magistério eixo das políticas atualmente vigentes na área - traz consigo novos elementos, pressupondo a elevação do estatuto social e da autonomia dos professores (LANG, 1999; BOURDONCLE, 2000; ALTET, 2001). No que se refere ao estatuto social, observam-se dois movimentos simultâneos, muitas vezes assumidos como coincidentes. Internacionalmente, ocorrem esforços para a elevação do nível educacional dos que pretendem ingressar na carreira docente, de quem são exigidos diplomas e títulos acadêmicos que atuam no campo como capitais culturais institucionalizados (BOURDIEU, 1979), com os quais eles podem alcançar alguma distinção. Nesse mesmo sentido, a formação específica para o magistério também tem sido alçada a níveis mais elevados do sistema educacional, podendo oferecer aos professores ganhos no que se refere aos capitais culturais incorporados (BOURDIEU, 1979). Esses capitais, na forma de conhecimentos especializados e formalizados, lhes favoreceriam relações mais racionais, reflexivas e críticas com a prática pedagógica (PERRENOUD, 2001; RIA; LEBLANC; SERRES; DURAND, 2006). Ademais, esses conhecimentos oferecem-lhes recursos discursivos - termos, expressões, citações etc. - por meio dos quais eles podem justificar e legitimar suas opções pedagógicas.

E essa elevação do estatuto social dos professores, empreendida por meio da aquisição de capitais culturais em diferentes estados (incorporados e institucionalizados), pode ser revertida em lucros significativos no que se refere à autonomia profissional. Em sociedades nas quais os conhecimentos produzidos por meio de práticas acadêmicas alcançam alto grau de legitimidade, os capitais culturais conquistados pelos professores, em uma formação de alto nível, são considerados como signos de competência profissional.

No entanto, para que o reconhecimento dessa expertise angarie lucros mais expressivos para os professores, é necessário que ela lhes possibilite obter algum controle sobre os processos de formação das novas gerações docentes e conquistar um estatuto mais bem definido no mercado da formação docente. A formação profissional, "extero-referente" (BOURDONCLE, 2000), visa ao exercício de uma profissão que se realiza e se governa no exterior da universidade, devendo, portanto, prever a participação de agentes diversos: pesquisadores acadêmicos dedicados ao ensino superior, à pesquisa e à extensão; formadores experientes na pro- 
fissão de referência; profissionais em exercício que colaboram com os estágios curriculares supervisionados e acompanham a inserção dos novatos na carreira; além dos administradores do grupo profissional, que autorizam os estágios e atuam na colocação profissional dos formados.

Sob tal perspectiva, a profissionalização dos professores requer a confluência de dois movimentos no campo da formação docente: 1) a elevação do nível de certificação dos professores, acompanhando a elevação do nível educacional da população mais geral, mas que é caracterizada também por uma forte valorização dos saberes acadêmico-educacionais; e 2) uma maior proximidade da formação com as práticas profissionais docentes, com a consideração da escola como locus formativo privilegiado.

Tais exigências implicam contradições diversas para o modelo formativo em vigor (MAUÉS, 2003; BOURDONCLE, 2007; SARTI e BUENO, 2007), motivando discussões sobre a estrutura e o currículo dos cursos que formam professores. Tais discussões evidenciam a importância que a experiência prática tem assumido para a formação, como meio de preparar melhor os professores para o trabalho docente (BANCEL, 1989; HOLMES GROUP, 1995; BRASIL, 2002) e apontam para a afirmação de uma modalidade formativa caracterizada pela alternância entre o local de formação e a escola. Sob uma lógica socioprofissional (SOREL, 2005), a formação docente então se define como um processo de socialização, que deve possibilitar ao sujeito organizar os saberes aprendidos para serem empregados em situação de ensino. Evidencia-se, nesses termos, uma convergência internacional para a integração entre o local de trabalho e a formação docente (MALET, 2010). A escola, enquanto espaço onde os saberes docentes são mobilizados, passa a ser considerada central para a formação do magistério, enquanto se espera que os professores experientes assumam uma nova identidade profissional, como formadores de seus pares.

As práticas de acompanhamento na formação docente tendem a ganhar maior evidência e contornos mais profissionais. $\mathrm{O}$ acompanhamento vem-se estabelecendo na área como possibilidade de uma formação que ultrapasse as funções tradicionais e que se integre melhor à vida adulta, concebida, em seu dinamismo, sob uma perspectiva transicional (ROQUET, 2009). A formação permanente impõe-se então como paradigma no campo formativo, ao passo que a profissão docente é redefini- 
da enquanto um conjunto de competências profissionais adquiridas em uma formação ao longo da vida (MALET, 2010).

Considerando o contexto internacional, Regis Malet (2010) identifica a emergência de novos atores no campo da formação docente que, localizados na interface entre a formação e a profissão, buscam criar pontes entre a universidade e os estabelecimentos de ensino, ao mesmo tempo em que intentam fazer face às pressões e exigências da docência. Tais atores, responsáveis pelas práticas de acompanhamento, são chamados a assumir uma identidade profissional específica, baseada tanto em sua própria expertise da prática docente quanto no desafio de intervir nas aprendizagens e na iniciação profissional de novos professores.

Essa formação pelo acompanhamento rompe com o modelo mais tradicional de formação docente, representado pelo antigo mestre de aplicação das Escolas Normais (professor "exemplar" a ser imitado pelos futuros professores). Não se trata mais de observar o modelo para aplicálo às situações de ensino, mas de experimentar o trabalho docente sob a orientação de um formador capaz de empregar dispositivos formativos que ofereçam suporte, face a face, a um iniciante ou a um profissional menos experiente, a fim de que ele descubra suas próprias possibilidades de atuação. Esse ideal de formação já se insinuava no trabalho desenvolvido nas últimas décadas de existência das Escolas Normais francesas, com a substituição do maître d'application pelo instituteur maître formateur ${ }^{3}$ e se fortaleceu naquele país com a criação dos IUFM, na década de 1990.

Nos últimos anos, a figura desses formadores tem alcançado maior centralidade no debate internacional sobre a formação docente, e seu trabalho vem alcançando contornos cada vez mais elaborados, com o investimento na produção e no aprimoramento de dispositivos voltados para sua atuação. Esse lugar profissionalmente mais bem definido dos formadores de professores pode representar mudanças significativas nas relações estabelecidas no campo da formação docente, especialmente em um contexto marcado pela universitarização do magistério e pela forte influência dos especialistas da educação na proposição de saberes acadêmico-educacionais. Esse panorama suscita questionamentos referentes ao papel que os professores da educação básica, potenciais formadores de seus pares, assumem nesse espaço concorrencial, bem como às novas configurações que o campo da formação de professores poderá assumir. 
Questionamentos nesse sentido nortearam uma investigação ${ }^{4}$ que teve como referencial o contexto francês da formação de professores para os anos iniciais da escolarização básica (premier degrê),${ }^{5}$ cujo interesse justifica-se por duas razões principais. Primeiramente, porque, na França, historicamente, os professores da escola básica desempenham um papel bastante ativo e assumem um estatuto definido na formação docente, sendo selecionados para a função de formadores por meio de um exame específico e recebendo remuneração pelo trabalho que então realizam. Esse estatuto de formador não encontra correspondentes no cenário brasileiro. Mesmo que tenhamos, no Brasil, assumido o modelo francês de formação docente como principal inspiração para a criação de nossas antigas Escolas Normais (TANURI, 2000) e que a formação dispensada aos futuros professores brasileiros tradicionalmente inclua a realização de estágios supervisionados - com a observação do trabalho de professores experientes ou com atividades de regência em sua classe - não temos ainda como política o reconhecimento dos professores do ensino básico como formadores ativos de seus pares. Não contamos com dispositivos sistemáticos para sua seleção e formação, não lhes atribuímos uma designação específica no sistema educacional e comumente não os remuneramos pelo desempenho de suas atividades formativas junto aos estagiários.

O contexto francês merece atenção, também, em função da recente masterização da formação docente implementada, em um primeiro momento, por meio da integração dos Institutos Universitários de Formação de Professores (IUFM) às universidades. ${ }^{6}$ Seguindo a reforma do ensino superior europeu, a formação profissional docente, na França, passou a requerer cinco anos de estudos universitários, sendo elevada ao nível de mestrado. Emergem apreciações críticas sobre a experiência formativa dos IUFM (1990-2010) e o debate sobre os possíveis caminhos que a formação docente seguirá naquele país (BARRÈRE; LEGRAND, 2009). A formação dos professores franceses vem assumindo novas configurações, nas quais são alterados, entre outros aspectos, o estatuto e as funções dos agentes que dela participam. A identificação de algumas das características dessas configurações emergentes, bem como dos movimentos e tendências que então se delineiam, mostra-se, a um tempo, pertinente e instigante.

Seguindo essas pistas iniciais, empregaram-se procedimentos diversos e complementares para realizar uma investigação sobre o estatu- 
to que os professores da escola básica passam a assumir na formação de professores franceses, agora realizada no nível do mestrado. Inicialmente, procedeu-se a uma revisão da literatura e ao estudo de documentos oficiais sobre o papel dos professores formadores ${ }^{7}$ na formação docente e também sobre o processo de universitarização do magistério francês. Tais estudos preliminares possibilitaram a organização da etapa seguinte da pesquisa, realizada junto ao IUFM de Versailles, que então assumia a formação docente em quatro grandes Departamentos ${ }^{8}$ da região parisiense. As atividades de campo caracterizaram-se pela realização de entrevistas com sujeitos diversos envolvidos na formação docente e por observações de situações formativas, na universidade e nos estágios supervisionados. Essa etapa de trabalho empírico foi realizada entre setembro de 2011 e fevereiro de 2012, período marcado por intensos debates sobre o processo de masterização que se configurava. Assim, as atividades de pesquisa, no contexto francês, foram caracterizadas também pelo estudo de documentos diversos (boletins oficiais, relatórios, programas de mestrados profissionais etc.) divulgados à época.

As decisões e o ritmo assumidos no âmbito do trabalho de campo da pesquisa foram significativamente marcados pelo dinamismo do momento em que foi realizado. Havia uma circulação intensa de informações e opiniões sobre a nova configuração da formação dos professores, e, ao serem questionados sobre as mudanças em curso, alguns dos entrevistados ressaltaram tratar-se de um momento de verdadeira transição na formação docente. Pareciam sempre instigados a falar sobre o tema, explicando à pesquisadora estrangeira o histórico, os detalhes e as contradições do processo. As posições diante das mudanças em curso eram sempre passionais. A atmosfera mostrava-se, pois, bastante favorável para a realização da pesquisa, e, de cada depoimento, emergiam novas informações sobre o modo como a masterização alterava relações e papéis historicamente estabelecidos em torno da formação dos professores franceses. 


\section{Os professores da escola e a formação docente na França: das Escolas Normais aos mestrados profissionais}

$\mathrm{Na}$ França, professores dos anos iniciais da educação básica atuam como tutores na formação inicial de seus pares desde o final do século XIX, quando foi instituída a rede de escolas anexas e de classes de aplicação, em que os normalistas realizavam os estágios de formação profissional, em classes de professores experimentados (PELPEL, 1996). Os professores de aplicação, ${ }^{9}$ que acolhiam estagiários em suas classes, eram escolhidos em função da excelência de seu trabalho pedagógico, para atuarem como modelos para os estagiários em formação.

Somente em 1962 foi criado um exame para selecionar os professores de aplicação, o CAEAA $^{10}$ (Certificado de aptidão para o ensino nas escolas anexas e de aplicação), o que significou maior estabilidade no desempenho dessa função. Patrice Pelpel (1996) esclarece que os critérios de seleção empregados nesse exame priorizavam a excelência docente dos candidatos, mais do que suas qualidades como formadores de professores. Tal situação foi gradualmente alterada nas décadas seguintes, e, em 1973, os selecionados pelo CAEAA passam a ser denominados "professores formadores"," nomenclatura que enfatiza suas atribuições formativas. Em 1985, foi criado o CAFIMF $^{12}$ (Certificado de aptidão às funções de professor-formador), exame ainda hoje em vigor, que seleciona os candidatos a formador tanto por suas qualidades docentes quanto por suas competências para a formação profissional (PELPEL, 1996).

Seguindo a tendência internacional de universitarização da formação de professores, as tradicionais Escolas Normais francesas foram substituídas, nos anos 1990, pelos IUFM, criados pela Lei de Orientação da Educação de 1989, como estabelecimentos públicos de ensino superior responsáveis pela formação inicial e continuada dos professores de todos os níveis da Educação Nacional (primeiro e segundo graus) e dos conselheiros principais da educação. ${ }^{13}$ De acordo com a referida lei, cada uma das academias francesas ${ }^{14}$ deveria abrigar um IUFM, que, por sua vez, estabeleceria ligações com pelo menos uma das universidades vinculadas à mesma academia.

A criação dos IUFM representou uma elevação, ao nível superior, da escolarização dos professores primários franceses, ao mesmo tempo em que possibilitou reunir em uma única instituição a formação 
dos professores dos diferentes níveis da educação nacional. Até então, como explica Bourdoncle (1990), os professores primários eram formados nas Escolas Normais, sob um "modelo carismático" de formação, enquanto os professores do segundo grau (collège e lycée) ${ }^{15}$ recebiam uma formação cultivada, universitária, marcadamente disciplinar e pouco profissionalizante. Com os IUFM, objetivou-se favorecer a emergência de uma nova identidade profissional docente, que agregasse todos os professores da educação básica em torno da expertise no ensino. Segundo o Relatório Bancel (1989), documento fundador para os IUFM, a formação a ser oferecida por tais institutos visaria ao desenvolvimento de uma "profissionalidade global” (RELATÓRIO, 1989, p.3) dos futuros professores. Tal formação deveria oferecer-lhes um "sólido saber universitário" (RELATÓRIO, 1989, p.3), obtido pelo contato com espaços de produção de conhecimento, mas, também, o desenvolvimento de competências diretamente ligadas às atividades docentes realizadas nos estabelecimentos escolares.

A formação oferecida nesses institutos foi organizada então em dois anos, independentemente do concurso pretendido pelo estudante. ${ }^{17}$ Após três anos de estudos universitários (a Licence), os estudantes que tinham a intenção de se tornar professores poderiam ingressar no IUFM para cursar o primeiro ano e assim se preparar para o concurso nacional de recrutamento docente. Segundo preconizava o Relatório Bancel (1989), no primeiro ano de estudos, os futuros professores do primário deveriam receber os complementos de formação que lhes possibilitassem uma "polivalência relativa" (RELATÓRIO, 1989, p.14). Tal formação deveria ser caracterizada por uma dimensão prática ligada a saberes acadêmicos. Os futuros professores do secundário (collèges e lycées) deveriam receber uma "formação científica complementar, acompanhada de um ensino de didática" (RELATÓRIO, 1989, p.14), em ligação estreita com as universidades. Para os futuros professores do ensino tecnológico e profissional, os IUFM deveriam oferecer uma formação organizada em estreita relação com as empresas e estabelecimentos de ensino superior.

Já o segundo ano de formação no IUFM era destinado exclusivamente aos recém-admitidos nos concursos de recrutamento. A esses "funcionários estagiários" seria oferecida uma formação marcadamente profissional. A proposição feita pelo Relatório Bancel era a de que tal formação reunisse os estágios, a formação nos conteúdos de ensino e a didá- 
tica das disciplinas, integrando ainda as especificidades do ensino na école maternelle, na école elementaire, no collège e no lycée.

No caso da preparação dos futuros professores dos anos iniciais, eram propostos diferentes tipos de estágio, organizados de forma a possibilitar uma progressividade na formação (PELPEL, 2003). No primeiro ano, os estudantes realizavam um estágio de prática acompanhada, que constituía em uma primeira aproximação dos mesmos com a experiência docente. Para tanto, os estudantes eram acolhidos em classes da educação infantil ou fundamental, onde deveriam realizar observações e assumir algumas atividades docentes, em um ambiente controlado e protegido. $\mathrm{O}$ estudante contava com a atuação dos professores de acolhimento temporário, ${ }^{16}$ para recebê-los, e/ou dos professores formadores, que, além de acolher estudantes em sua classe, assumiam a função de aconselhá-los quanto à prática de ensino.

No segundo ano, já concursado e assumindo a função de "funcionário estagiário", o estudante do IUFM deveria realizar períodos de estágio de prática acompanhada e, também, nove semanas de "estágio em responsabilidade", durante o qual assumia uma classe de forma mais autônoma, sem a presença do professor titular. Esse tipo de estágio, realizado em responsabilidade, tem em vista possibilitar ao estagiário mobilizar todos os componentes do ensino em um período limitado (PELPEL, 2003). Durante o estágio em responsabilidade, o funcionário estagiário recebia visitas periódicas de um professor formador e de formadores do IUFM, que deveriam aconselhar-lhe e avaliar, validando ou não seu estágio (do que dependia sua titularização como professor na Educação Nacional). De acordo com os dados reunidos em campo por meio das entrevistas, a validação dos estágios em responsabilidade era decidida conjuntamente pelos formadores do IUFM e os formadores de campo (os professores formadores que atuam nas escolas).

Segundo Pelpel (1996), a criação dos IUFM não implicou modificações significativas quanto ao perfil e estatuto dos professores formadores. Já no que se refere ao corpo de formadores internos à instituição, algumas mudanças ocorreram com a inclusão de professores-pesquisadores, que, no entanto, figuraram sempre como minoria em um grupo constituído majoritariamente por professores do segundo grau (PRCE, professeur certifieie ou PRAG, professeur agreg $\left.{ }^{19}\right)$, e, em menor número, por profes- 
sores do primeiro grau, os PREC (professeurs des écoles). Esses formadores egressos da escola, tradicionalmente responsáveis pela formação oferecida nas Escolas Normais, ingressavam nos IUFM por meio de concurso para atuar em tempo completo ou parcial, mantendo nesse segundo caso também seu trabalho na escola.

A esse respeito, Bourdoncle (2007) enfatiza que a manutenção do estatuto de formador por parte de professores sem titulação acadêmica (doutorado) representa um dos indícios de que os IUFM não assumiram o caráter científico, cultural e profissional tradicionalmente esperado das universidades. Trata-se, para esse autor, de um caso de "falsa universitarização“ (BOURDONCLE, 2007, p.139), posto que não significou, de fato, uma integração organizacional da formação às estruturas universitárias habituais (no que se refere, sobretudo, à centralidade das atividades de pesquisa e ao estatuto de professor-pesquisador assumido pelos encarregados da formação universitária).

Esse cenário vem sendo alterado em função da já referida reforma do ensino superior europeu, que preconiza a formação profissional docente no nível de mestrado, requerendo cinco anos de estudos universitários. A Lei no 2005-380, de 23 de abril de 2005, impôs uma importante mudança estrutural aos IUFM, decretando que os mesmos seriam progressivamente integrados às universidades, que então passariam a administrá-los como escolas internas. Em 2008, foi iniciada a integração dos IUFM às universidades, e, desde o início do ano letivo de 2010, os estudantes franceses que pretendem se tornar professores dos anos iniciais devem obter a licence (três anos) e depois concluírem um mestrado profissional de dois anos.

Entre as opções de mestrado profissional que foram oferecidas pelas universidades na primeira fase do processo de masterização da formação de professores (2010-2012), algumas eram especialmente voltadas à formação dos professores para o premier degré. Esse curso poderia ser oferecido por qualquer universidade, mesmo aquelas que não incorporaram um IUFM como escola interna. Como, a partir da Lei no 2007-1199, de 2007, as universidades francesas são consideradas autônimas, elas gozam de liberdade para propor seus cursos. Assim, os mestrados voltados para os candidatos ao concurso de recrutamento de professores das escolas (CRPE) recebiam diferentes denominações e eram organizados de modos diversos. ${ }^{20}$ 
O contexto que então se delineou no período investigado foi de intensa concorrência por estudantes entre as universidades que ofereciam os cursos de mestrado. Os IUFM passaram assim a dividir o mercado da formação de professores com outros estabelecimentos de ensino, o que representou uma significativa redução do número de estudantes matriculados em seus campi. No caso do IUFM de Versailles, focalizado pela investigação, o ano letivo 2009/2010 21 (que antecedeu a implementação da reforma) contou com aproximadamente cinco mil estudantes matriculados. Já a segunda turma de ingressantes nos mestrados profissionais (2011/2012) foi formada por apenas 1.900 estudantes.

A essa diversidade de propostas de formação por parte das universidades somaram-se os diferentes modos como os Departamentos se apropriaram das orientações legais sobre a reforma na formação dos professores. Assim, a formação docente implementada naquele primeiro momento de masterização na França assumiu versões locais de organização, em função tanto da proposta de cada universidade, quanto das maneiras como a mesma articulou-se com orientações departamentais (para a cooperação para a realização dos estágios, por exemplo). Os estágios supervisionados nas escolas elementares continuaram a ocorrer, mas o modo como foram organizados dependia do programa de formação oferecida pela universidade e dos convênios estabelecidos para esse fim.

No que se refere ao corpo docente que atuava nos mestrados profissionais, observou-se uma continuidade do contexto vivenciado anteriormente nos IUFM, já que, ao absorverem esses institutos, as universidades incorporaram também os professores de primeiro e segundo graus que aí atuavam como formadores em tempo integral ou parcial (os PRAG, os PRCE e os PREC). A inclusão desses formadores no quadro docente das universidades impôs desafios importantes, visto que passaram a atuar em um ambiente mais fortemente marcado pela cultura e a hierarquia universitária. Caso quisessem compor os laboratórios de pesquisa da universidade, esses formadores deveriam obter o diploma de doutor, assumindo novo posto e nova identidade profissional, como professor pesquisador.

E o movimento de universitarização atingiu mesmo aqueles que não pretendiam ingressar na carreira universitária, já que muitos formadores foram impelidos a obter ao menos o nível de escolaridade pleiteada pelos estudantes que eles passaram a atender na universidade. 
Consolidou-se, então, uma tendência de oferecimento de mestrados profissionais voltados para a formação de formadores. ${ }^{22}$ Para serem admitidos nesses cursos, os candidatos devem atestar, pelo menos, cinco anos de experiência profissional, além de diploma comprovando a realização de um ano de mestrado (M1), que pode ser substituído por um documento que certifique seus conhecimentos profissionais e relativos às problemáticas da formação (VAPP85 ${ }^{23}$ ). Assim, muitos formadores passaram do papel docente ao papel de estudante, não raras vezes na própria universidade em que atuam, tendo colegas como professores.

Mas, entre as mudanças trazidas por aquela (nova) universitarização da formação docente, a que mais diretamente parecia incidir sobre o papel e o trabalho dos formadores - de campo ou do IUFM - era a clara separação entre a formação inicial docente pré-concurso e pós-concurso que então se delineava e que acompanhava separações mais amplas e estruturais. Ao serem incorporados pelas universidades, como escolas internas, os IUFM vincularam-se ao Ministério do Ensino Superior e da Pesquisa. Nessa nova organização, as universidades passaram a se encarregar da certificação no mestrado dos estudantes que se dirigem aos concursos nacionais, enquanto as Academias (ligadas ao Ministério da Educação) responsabilizam-se pela seleção dos novos professores e pela organização de sua formação profissional em serviço. Colaborações entre as duas instâncias eram possíveis, desde que reguladas por convênios.

Do ponto de vista hierárquico, antes dessa separação estrutural, os professores formadores que atuam nos estágios respondiam tando ao inspetor da Academia quanto ao reitor do IUFM. A partir de 2010, com a promulgação do Boletim Oficial no 29 do Ministério da Educação, ficou estabelecido que eles passariam a atuar sob a autoridade exclusiva do inspetor da Academia, diretor dos serviços departamentais da Educação Nacional. Sua atuação nos mestrados profissionais passou a estar regulada por convenções assinadas entre a Academia e a reitoria da universidade. Assim, a vinculação dos professores formadores ao IUFM deixou de ser 'automática', e seu espaço na formação inicial pré-concurso dos futuros professores foi significativamente reduzido. Por outro lado, sua atuação no acompanhamento de professores recém-concursados, responsáveis por uma classe, mas ainda não titulares, passou a ser considerada como dispositivo central de formação, em substituição ao ano como funcionário estagiário no IUFM, que era antes previsto para os recém-con- 
cursados. De acordo com o referido Boletim, o professor formador passou a figurar como

[...] ator essencial da formação dos professores do primeiro grau, como experts da prática de sala de aula e da polivalência do ofício, e como garantia de uma articulação eficaz e comprovada entre os saberes teóricos e a prática profissional, capaz de analisar com suficiente distância a diversidade de situações e de processos de ensino para perceber seus efeitos (FRANÇA, 2010, p.1). (Tradução do autor).

Enquanto os professores formadores assumiam espaço cada vez mais estratégico na formação em serviço oferecida pela Educação Nacional, seus colegas, formadores no IUFM, viviam um período de indefinições. Do ponto de vista funcional, a absorção dos IUFM pelas universidades e a sua decorrente vinculação ao Ministério do Ensino Superior e da Pesquisa traziam-lhes implicações profissionais importantes. Como professores da escola básica, sua vida funcional continuava vinculada ao Ministério da Educação. Se pretendessem uma progressão mais expressiva na carreira docente (que não fosse aquela decorrente dos anos de vinculação profissional), deveriam retornar à Educação Nacional, abandonando o cargo que ocupavam junto ao IUFM. Na universidade, além das já referidas dificuldades de inserção profissional, a diminuição do contigente de estudantes nos IUFM reverteu-se em desafios para que esses formadores mantivessem uma carga horária mínima. Uma das alternativas encontradas por eles foi assumir um número maior de visitas aos estudantes durante os estágios em responsabilidade nas escolas, atividade que antes partilhavam com os professores formadores de campo. Observa-se, pois, que, naquele contexto de separação entre a formação inicial docente pré-concurso e pós-concurso, afirmou-se uma acentuada tendência de isolamento dos formadores que atuavam nesses dois momentos formativos.

Tal é o cenário no qual a pesquisa aqui referenciada foi levada a efeito. A seguir, são apresentados dados mais específicos reunidos em campo, que nos possibilitam um flagrante de certos aspectos das mudanças então em curso, especialmente no que se refere ao trabalho, ao espaço e ao estatuto assumido pelos professores que se ocupam da formação docente na França. 


\section{A universitarização, 0 mercado francês da formação docente e o lugar dos professores formadores}

No momento em que a pesquisa foi realizada, o IUFM de Versailles integrava-se como escola interna à Universidade de CergyPontoise, na região de Ile-de-France e, desde 2010, oferecia mestrados profissionais relacionados à educação e à formação em áreas ligadas à cultura. ${ }^{24}$ Esses mestrados eram divididos em quatro especialidades referentes: 1) ao ensino no premier degré ou na concepção de projetos educativos e culturais; 2) às profissões da educação e da formação nos domínios tecnológicos e profissionais; 3) ao atendimento de necessidades educativas específicas; e 4) às atividades de conselho, administração, formação e pesquisa no âmbito educativo. Além dos mestrados, a instituição oferecia cursos em nível de graduação de tipo pluridisciplinar (Letras e Matemática) e profissional (Gastronomia e Hotelaria).

O trabalho formativo acima referido era realizado em cinco campi, distribuídos entre quatro Departamentos: Val-d'Oise, Haute-deSeine, Yvelines e Essonne. Os estudantes dos diferentes cursos voltados especificamente para a área educacional recebiam formação ligada ao Concurso de recrutamento de professores do primeiro grau (CRPE), o Concurso de ensino técnico e profissional (CAPET, CAPLP) ou para o Concurso de recrutamento de conselheiros principais de educação (CRCPE).

Em fevereiro de 2012, o corpo docente daquele IUFM era composto por 281 profissionais contratados em tempo integral ou parcial: 200 professores do nível primário e secundário (PREC, PRAG e PRCE) e 81 professores-pesquisadores. Esses dados gerais estavam, à época, disponíveis no site da instituição. No entanto, alguma dificuldade foi enfrentada para se obter informações mais precisas sobre a atuação dos professores do nível primário nos mestrados profissionais oferecidos pelo IUFM. Para o departamento de recursos humanos da universidade, os formadores oriundos do primeiro e do segundo graus estavam reunidos em um mesmo grupo, indistintamente. Foram os coordenadores da formação oferecida em cada campus que forneceram informações a respeito. Segundo os dados reunidos, havia 35 postos de formadores ocupados por professores do primeiro grau nos diferentes campi do IUFM, sendo que, em 26 casos, os professores dedicavam-se integralmente ao trabalho de 
formação docente. Os demais nove postos eram ocupados por professores que dividiam seu tempo entre a formação docente e o trabalho nas escolas. Dados reunidos durante a investigação indicam que alguns dos formadores atuavam em mais de um campus da universidade.

O mestrado oferecido aos estudantes interessados no CRPE denominava-se "Profissões da educação e do ensino do primeiro grau"25 e dividia-se em dois percursos específicos: "Ensinar na educação infantil e elementar" e "Conceber projetos educativos e culturais em parceria". ${ }^{26}$ A pesquisa realizada focalizou mais especificamente a organização e funcionamento do primeiro percurso, em sua modalidade presencial (o mesmo era oferecido nas modalidades em alternância e à distância). $\mathrm{O}$ curso era realizado em dois anos, com uma carga horária de 619 horas no primeiro ano (mestrado 1) e de 554 horas $^{27}$ no segundo ano (mestrado 2). No que se refere mais especificamente aos estágios, o mestrado 1 previa a realização de 54 horas de atividades de observação e 54 horas de prática acompanhada. No mestrado 2, os estudantes deveriam realizar entre 12 e 24 horas de observação como preparação para a realização de 108 horas de estágio em responsabilidade. O estágio de observação poderia ser realizado em classes de professores formadores ou de professores de acolhimento temporário, ambos designados pela instituição de formação.

Durante as quatro semanas do estágio em responsabilidade, os estagiários deveriam assumir todas as atividades de uma classe, sem a presença do professor titular. $\mathrm{Na}$ maior parte dos casos, o estágio era realizado na classe de um professor de acolhimento temporário (MAT), e o estagiário recebia visitas de aconselhamento por parte de formadores do IUFM (PRAG, PRCE ou PREC) e de formadores enviados pelo inspetor da academia à qual se vinculava a escola (professor formador ou conselheiro pedagógico). Além das visitas de aconselhamento, ao final do estágio, o estudante recebia visitas de avaliação por parte de um formador do IUFM e também de um agente enviado pela inspetoria acadêmica (novamente um professor formador ou um conselheiro pedagógico), que elaboravam relatórios a serem considerados para a validação do estágio. Sobre a condução desse processo, Henriette, ${ }^{28}$ professora formadora há mais de dez anos, explica:

Há uma avaliação a ser feita (sobre o estágio do estudante) que será levada em consideração pelo IUFM para a validação do mestrado. Mas isso é completa- 
mente espantoso, pois nós vamos visitar o estagiário, nós e o professor do IUFM. Cada um de nós faz um relatório sobre a visita, mas a validação do estágio não é feita por nós! [...]. Nós não participamos mais do conselho, não nos reconhecem, não mais [...]. Antes da masterização, nós participávamos da comissão. Cada um fazia seu relatório e nós nos reuníamos com os professores do IUFM. Havia uma coisa realmente muito organizada, oficial, em que nós validávamos juntos o sucesso e a passagem de cada estagiário. Havia equipes de formadores constituídas por professores formadores e por professores do IUFM, e nós fazíamos as coisas juntos. Nós sabíamos exatamente o que cada professor dizia sobre o estagiário e eles sabiam o que nós dizíamos. Havia muita discussão, mas nós estávamos informados e as decisões eram tomadas conosco. Hoje... eu continuo fazendo o relatório com responsabilidade [...] mas eu não sei como ele será interpretado e como o estagiário será avaliado [...] (Entrevista, 03/02/2012). (Tradução do autor).

O depoimento de Henriette ressalta a redução do espaço de participação dos professores formadores na formação oferecida pelo IUFM após a masterização. Embora alguns deles continuassem atuando na avaliação dos futuros professores, não ocupavam mais posições nos conselhos que decidiam sobre a validação dos estágios. Assim, deixavam inclusive de estabelecer relações mais sistemáticas com seus pares, que então atuavam junto à universidade. Marianne, professora formadora há quatro anos, também lamentava que a masterização tivesse implicado uma ruptura entre o trabalho realizado pelos formadores de campo e os formadores que atuam no IUFM

Havia um grande trabalho de trocas entre o professor formador e os professores do IUFM [...] mas agora não há mais trocas entre nós... pode haver, se nos conhecermos, mas a priori não há. Como exemplo, no ano passado, eu tinha em minha classe uma jovem professora estagiária (já concursada) e eu me encontrei com uma professora do IUFM que tinha sido sua professora e que a conhecia e ela me deu elementos sobre a maneira como ela trabalhava. Mas foi por acaso, de outro modo, não há trocas. Há, hoje, uma espécie de cisão entre o trabalho dos professores e nosso trabalho. É uma pena, pois nós trazemos pontos de vista diferentes. [...] a masterização nos afastou do IUFM como escola interna da universidade. Antes, nós podíamos intervir junto aos estagiários, aos estudantes, como professores formadores, conhecedores da escola. Agora... talvez alguns o façam, mas não há lugares para nós, há trabalho para os professores, mas não trabalho suficiente para todo mundo [...] então não temos mais trocas sobre o conteúdo da formação e não temos mais trocas sobre os estagiários [...] (Entrevista, 04/01/2012). (Tradução do autor). 
Como destaca Marianne, a participação dos formadores de campo na formação inicial dos professores franceses não era mais 'automática', como fora tradicionalmente. Tal participação mostrava-se regulada por dispositivos burocráticos e tornava-se ainda mais escassa em função das novas condições de trabalho dos formadores do IUFM (que tinham dificuldades para manter sua carga horária, já que, como dito, houve uma importante redução do número de matriculados nos cursos do instituto). Assim, as relações estabelecidas de longa data entre os formadores do IUFM e os formadores de campo, que atuam nas escolas, estavam fragilizadas e colocadas em questão por falta de dispositivos institucionais que as estimulassem.

Como antes mencionado, a redução do espaço de atuação dos professores formadores na formação inicial dos professores (préconcurso) foi acompanhada por uma valorização de sua atuação na formação em serviçio oferecida pela Educação Nacional. Essa nova perspectiva de atuação era vista com entusiamo por Marianne:

No que se refere à parte de acompanhamento, tutorado e conselho, o trabalho do professor formador é muito mais interessante agora do que antes da masterização, pois nós seguimos o estágiário ${ }^{29}$ do início ao fim do ano. É maravilhoso! Nós vemos alguns chegando do zero, sem saber nada sobre ensino, e, depois de dois meses de trabalho, vemos o progresso... É muito mais rico agora, pois nós vemos o fruto de nossas trocas com o professor estagiário. [...] Eu já pensei em me tornar formadora do IUFM em tempo parcial, dois dias no IUFM e dois dias na escola, mas eu tenho medo de perder o trabalho de formadora de campo agora que ele se torna ainda mais interessante (Entrevista, 04/01/2012). (Tradução do autor).

No entanto, essas mesmas mudanças relativas ao trabalho a ser realizado e ao papel dos professores formadores foram consideradas de forma diferente por outros professores. Jean Paul, professor formador por 25 anos - primeiramente na Escola Normal e, depois, no IUFM explica por que resolveu abandonar a função após a masterização:

Eu tenho impressão de que não há mais formação. O que se chama de formação hoje é mais avaliação do que formação, mais remediação. Nós visitamos o professor estagiário (recém-concursado) e dizemos "Isto não está bom", mas nós não o formamos antes. [...] Eu vejo jovens que são muito bons, que têm uma boa bagagem cultural e que trabalham muito, esses jovens trabalham muito, muito. Mas eles estão perdidos. Quando você vai visitá-los 
na classe... e nós temos muito pouco tempo para visitá-los... nós temos uma hora de discussão com eles! Não se pode fazer a formação em uma hora, é necessário mais tempo. É como todas as profissões, tem de aprender. Não há só a teoria, tem a prática. Se fizéssemos o mesmo com os pilotos de avião ou com os médicos, seria dramático! Dizer: "Assuma, comece a pilotar e depois a gente vê se está bom ou não..." (risos). Foi por isso que eu decidi deixar a função de professor formador. Tenho a impressão de que não se trata mais de formação, mas sim de remediação. Eu não gostaria de dizer que participei disso (Entrevista, 14/11/2011). (Tradução do autor).

As mudanças na atuação dos professores formadores acompanhavam mudanças na lógica e na estrutura da formação proposta. No formato anterior, a formação era realizada pelos IUFM em estreita ligação com a Educação Nacional, havia uma ênfase na inserção profissional dos funcionários estagiários, por meio dos estágios em responsabilidade, realizados ao longo do segundo ano de formação e acompanhados por professores formadores de campo e formadores do IUFM. Na nova configuração, em que cada universidade organizava de forma autônoma a formação oferecida optando inclusive pelo tipo de estágio a ser realizado - e em que a atuação dos formadores de campo não era mais 'automática', a dimensão socioprofissional da formação havia sido deslocada para a formação em serviço, durante os estágios "em situação" realizados pelos professores ingressantes, recém-concursados. Trata-se de uma formação que ultrapassava a alternância na formação inicial, pretendida pelo modelo presente nos IUFM, para se configurar em uma formação apoiada basicamente no trabalho.

Se a aprendizagem da docência deslocava-se, desse modo, para a situação de trabalho no magistério, restava às instituições de formação inicial um papel de menor destaque, mais vinculado à preparação dos candidatos para o concurso nacional de seleção dos novos professores. Essa flagrante fragilização da dimensão socioprofissional da formação inicial docente oferecida nos mestrados teve impactos bastante significativos para o papel e estatuto dos professores formadores que atuam no interior da universidade. Sua expertise no ensino não era requerida na formação realizada nos mestrados, não se revertendo, pois, em ganhos significativos nos embates simbólicos travados no interior da universidade. Como já ocorria nos IUFM, mas de forma ainda mais intensa e explícita, a permanência desses formadores nos quadros docentes requeria que se enquadrassem na lógica disciplinar imperante. Vincent, formador no IUFM há cinco anos, relatou sua experiência nesse sentido. 
[...] quando eu ingressei no IUFM, cheguei com competências profissionais que acabei não colocando a serviço da formação inicial porque assumi classes de primeiro ano voltadas, sobretudo, para a preparação ao concurso. Minhas competências foram absorvidas pela instituição. E eu, ingenuamente, acreditei que seria solicitado mais especificamente, em minhas competências, para o trabalho com os estagiários (segundo ano). Ora, no tempo do IUFM (antes da masterização), eu oferecia cursos sobre saberes acadêmicos, tal qual um colega vindo do segundo grau. Enfim, meu estatuto não foi assumido pela instituição (Grupo focal, 02/12/2011). (Tradução do autor).

Mais especificamente sobre as disputas simbólicas estabelecidas com os demais agentes da universidade, Sophie, também formadora no IUFM, acrescenta:

A integração dos IUFM e de seu pessoal à universidade não apagou uma clivagem já existente (no interior dos IUFM) e representações sociais fortemente arraigadas: se alguém leciona na escola maternal, considera-se que seja porque não tem competência para ensinar na escola fundamental; se leciona no fundamental, é porque não pode ensinar no ensino médio e assim por diante [...] (Grupo focal, 18/11/2011). (Tradução do autor).

E outro formador do IUFM, Pierre (que recentemente havia finalizado o doutoramento), destaca em maiores detalhes os capitais envolvidos nessas disputas.

Essa percepção social de uma hierarquia não dita é muito forte na França. E há uma outra coisa: a oposição entre uma visão disciplinar do ensino e a polivalência. Há quase que um combate entre a didática geral e as disciplinas de ensino. E o primeiro grau é sempre chamado a encontrar seu espaço: nós somos quase que obrigados a explicar à sociedade que ensinar nas classes do primeiro grau é uma profissão [...] O problema colocado pela masterização é que a universidade é disciplinar [...]. Isso traz para a universidade o problema da formação profissional: fazê-la passar pela universidade, que não está habituada a ela. Os professores formadores se encontram em uma implicação muito mais forte com um ensino profissional (Grupo focal, 18/11/2011). (Tradução do autor).

Os embates relatados por esses formadores do IUFM são um tanto previsíveis, tendo em vista que, como havia enfatizado Bourdoncle (2007), a universitarização da formação profissional impõe a figura do professor-pesquisador acadêmico, titular de um doutorado, 
como estatuto dominante, podendo resultar em uma "desvalorização e marginalização dos ensinamentos práticos" (BOURDONCLE, 2007, p.140). Nesse sentido, as desigualdades que já se interpunham entre professores formadores e professores-pesquisadores universitários no interior dos IUFM mostravam-se ainda mais evidentes com a masterização e a absorção desses institutos pelas universidades. A esse respeito, Chartier (2010) já havia ressaltado a necessidade de se atentar para o estatuto que a universidade concederia, no processo de masterização da formação docente, aos mestres formadores, recrutados por concurso, mas sem títulos universitários.

Nesse contexto, pertencendo aos quadros da universidade, sem, no entanto, ocuparem um lugar mais bem definido na formação oferecida nos mestrados profissionais e distanciados de seus pares formadores de campo, esses agentes pareciam enfrentar sentimentos de indefinição quanto à sua própria identidade profissional. Para os colegas da universidade, eles eram os "formadores", designação que acentua tanto sua origem vinculada ao campo profissional, quanto sua carência de diplomas acadêmicos (o que os fazia permanecer em um tipo de limbo, de onde não poderiam integrar os grupos de pesquisa e, portanto, vivenciar mais plenamente o ambiente universitário). De sua parte, seus colegas formadores de campo - como Henriette e Marianne - referiam-se a eles como sendo os "professores", agentes da universidade, vinculados a uma formação mais acadêmica e menos profissional.

Os caminhos assumidos por esses formadores, diante dos desafios que a vida na universidade lhes impõe (nesse momento não mais nos IUFM, mas nas ESPE), poderão trazer impactos significativos para o processo de universitarização da formação profissional docente na França. Sua permanência na formação universitária, sem, no entanto, assumirem compromissos mais estreitos com o trabalho acadêmico, especialmente no que se refere à pesquisa, pode ser considerada por alguns como indício da já referida "falsa universitarização" (BOURDONCLE, 2007), um dos limites imputados aos antigos IUFM. Já o investimento na obtenção de capitais mais valiosos no campo acadêmico (um título de doutor) deverá reverter-se em migrações profissionais para esse campo, o que favorece uma maior legitimidade acadêmica da formação inicial docente, que então permanece na via da universitarização, absorvendo mais inteiramente os agentes 
que a realizam, seus saberes e práticas. No entanto, essa opção dos formadores pela via acadêmica implica uma importante fragilização da dimensão socioprofissional da formação que realizam, podendo, no limite, comprometer a manutenção dessa modalidade formativa diante da valorização, no campo, de uma formação docente mais vinculada ao trabalho.

Esse é um cenário em que os professores da educação básica, tradicionalmente em posições de menor prestígio e poder no campo da formação docente (SARTI, 2012), têm seus capitais reavaliados. Em um movimento fugaz, impulsionado pelos discursos que, nas últimas três décadas, insistem na centralidade dos professores e de seus saberes, os professores começam a colher seus primeiros lucros no jogo da formação docente, mesmo que ainda como 'pequenos investidores' e apesar das várias contradições que persistem.

No contexto francês de masterização dos IUFM, aqui assumido como referência, os professores formadores de campo, reconhecidos em sua expertise no ensino e na formação docente, constituíram o grande trunfo do qual a Educação Nacional se valeu para implementar sua proposta de formação baseada na situação de trabalho, menos dispendiosa do ponto de vista econômico e potencialmente mais eficiente para a adequação dos novos professores como funcionários do Estado. Tal proposta formativa valorizava a figura dos professores formadores que atuam nas escolas, mas, ao mesmo tempo, parecia deflagrar um processo de funcionarização de seu trabalho, antes realizado junto aos IUFM. Sua função formativa passava a ser desenvolvida sob o olhar e a custódia de seu empregador, o Estado, que se valia de seus metacapitais (BOURDIEU, 2005) - econômicos, jurídicos, políticos etc. - para implementar o modelo formativo que lhe parecia mais vantajoso. Houve perdas, também, no que se refere ao espaço de atuação na formação inicial pré-concurso e nas relações estabelecidas com seus pares do IUFM.

Por outro lado, seguindo ainda a ótica proposta por Bourdieu (2005), é possível afirmar que esse modelo formativo baseado no acompanhamento da formação em situação trouxe alterações para a taxa de câmbio vigente nas transações realizadas no espaço da formação docente na França, possibilitando lucros significativos para esses professores formadores de campo. Seus saberes e experiências, certificados pelo concurso 
que os conduziu à função de formadores, garantiam-lhes espaço e reconhecimento, mesmo em um contexto de universitarização, marcado pelos mestrados profissionais. Essa taxa de câmbio favorável implicou, inclusive, a baixa procura desses professores pelos mestrados voltados especialmente à formação de formadores, que lhes possibilitariam obter titulação equivalente à dos professores iniciantes, de quem eram responsáveis pela formação em serviço.

Tal flutuação cambial aponta para uma inversão de tendência no mercado francês da formação docente. As análises dos dados reunidos pela pesquisa sugerem que a universitarização naquele contexto, realizada por meio da absorção dos IUFM e de seus formadores pelas universidades, implicou uma significativa fragilização da dimensão socioprofissional da formação inicial dos professores. Tendo sido implementada justamente com vistas à profissionalização do magistério, essa universitarização revelava seus efeitos contraditórios (disciplinarização, academização, afastamento do espaço de trabalho) e perdia valor diante do modelo da educação ao longo da vida, realizada na situação de trabalho. Aos mestrados profissionais oferecidos pelas universidades restava quase que exclusivamente a certificação do nível educacional dos candidatos à docência e sua preparação aos concursos (que seguiam muito acadêmicos, servindo a um Estado que empregava seus metacapitais para reservar para si a formação profissional docente, realizada já em serviço).

Paradoxalmente, o cenário que então se delineava estava próximo de uma "antiuniversitarização" (BOURDONCLE, 2009, p.21), em que a formação profissional docente propriamente dita passa a ser assumida por setores independentes das universidades. Embora, naquele caso, não se tratasse da constituição de uma estrutura de formação inicial docente superior não universitária (já que a certificação dessa formação seguia a cargo das universidades ${ }^{30}$ ), os efeitos contraditórios então identificados nos conduzem ao questionamentos sobre o lugar ocupado pela formação inicial docente no movimento de profissionalização do magistério na França. Fora da tutela do Estado e distanciada do campo profissional, absorvida pela estrutura disciplinar da universidade e reduzida à etapa de certificação e preparação para o concurso, a formação inicial dos professores franceses, outrora modelar, desvalorizava-se em um mercado formativo marcado pelo paradigma da formação permanente realizada 
em serviço. Sua sobrevivência nesse mercado parecia depender do emprego de recursos - econômicos, mas também simbólicos - que se mostrassem mais eficientes naquela configuração do campo. A proximidade com a pesquisa e com os especialistas da universidade podia render-lhe lucros, desde que ancorada em um movimento de real alternância com o espaço profissional docente e seus agentes. No caso francês, esse modelo formativo universitário em alternância com o trabalho realizado nas escolas segue como uma promessa a ser, quiçá, concretizada com as recém-criadas Écoles Superieures du Professorat et de l'Education.

Considera-se que a discussão desses efeitos imprevistos da universitarização da formação de professores na França possa oferecer elementos para um debate mais amplo sobre o movimento de profissionalização do magistério em outros países onde as universidades ocupam posição central na formação docente. Este é caso do Brasil, onde a universitarização do magistério movimenta um diversificado e aquecido mercado que se consolidou nos últimos anos em torno da formação dos professores da educação básica (SOUZA e SARTI, 2009).

Essa participação mais ativa da universidade na formação dos professores brasileiros integra um conjunto de estratégias políticas que, nas últimas décadas, foram implementadas no país com vistas ao enfrentamento de nossos problemas educacionais. O processo gradual de elevação do nível de certificação dos professores no Brasil, preconizado pela Lei de Diretrizes e Bases da Educação Nacional 9.394/96, assumiu contornos claramente acadêmicos, marcados pelo modelo universitário de organização dos saberes, no qual os professores da educação básica assumem pouco espaço e poder. Esse cenário de universitarização que se desenvolveu entre nós incita ao questionamento sobre o lugar ainda marginal que esses professores e seus saberes ocupam no campo nacional da formação docente (SARTI, 2012).

Os resultados da pesquisa aqui apresentada oferecem alguns elementos para a necessária problematização desse modelo de formação docente que assumimos no país. A universitarização não constitui uma via direta para a profissionalização do magistério; informação incômoda a ser considerada. Sem o enfrentamento dos muitos desafios que se interpõem para a construção de uma formação profissional docente de alto nível, a universitarização pode resultar na fragilização da dimensão socioprofissional da formação inicial dos professores, podendo, inclusi- 
ve, comprometer a legitimidade dessa etapa formativa no campo educacional. Essa desvalorização da formação inicial docente resulta em perdas para o movimento de profissionalização do magistério e, ao mesmo tempo, tende a minimizar as possibilidades de lucro da própria universidade no mercado da formação docente. Assim, se insistirmos em considerar a universidade como o lugar da formação de professores, será urgente empreendermos um sério debate sobre as condições que essa formação profissional requer, bem como sobre os desafios e tensões que então se impõem para a vida na universidade e para o modelo universitário ao qual estamos habituados. 


\section{NOTAS}

1 Instituts Universitaires de Formation de Maîtres.

2 No original francês, extéro-référencée.

3 A nova designação foi instituída em 1973. Voltaremos, mais adiante, ao tema.

4 Estudo de pós-doutorado realizado junto à Universidade de Cergy-Pontoise, sob a supervisão dos professores Max Butlen e Marie-Laure Elalouf. As atividades de pesquisa na França foram desenvolvidas com apoio financeiro da Fundação de Amparo à Pesquisa do Estado de São Paulo - Fapesp.

5 O Premier degré (primeiro grau), na França, é organizado em três ciclos, composto pelas três classes da école maternelle, responsável pelo atendimento das crianças a partir dos três anos de idade e pelas cinco classes da école élémentaire, na qual as crianças ingressam com a idade mínima de seis anos. No sistema educacional brasileiro, essa etapa da escolarização corresponde, respectivamente, à Educação Infantil e aos anos iniciais do Ensino Fundamental $\left(1^{\circ}\right.$ ao $5^{\circ}$ anos $)$.

6 O período aqui considerado refere-se à primeira fase do processo de masterização da formação de professores na França, que compreende três anos letivos (2010/2011, $2011 / 2012$ e 2012/2013). Nova fase desse processo foi implementada em setembro de 2013 (portanto, no início do ano letivo 2013/2014), com a criação das Escolas Superiores do Professorado e da Educação (Écoles Supérieures du Professorat et de l'Education - ESPE), que substituíram os IUFM.

7 Maîtres formateurs. Embora o termo maître possa ser traduzido como professor, seu tradicional emprego na França para designar os docentes dos anos iniciais é revelador quanto às representações sociais vinculadas ao trabalho nesse nível. Naquele país, o termo professor é mais comumente reservado aos docentes dos níveis mais elevados de ensino. Sem desconsiderar tais aspectos, opta-se aqui por empregar professor, termo com o qual os leitores brasileiros estão mais acostumados.

8 Divisões administrativas francesas.

9 Maîtres d'application.

10 Certificat d'aptitude à l'enseignement dans les écoles anexes et d'application.

11 Instituteurs maîtres formateurs (IMF), ou, simplesmente, maîtres formateurs (MF).

12 Certificat d'aptitude aux fonctions d'instituteur maître-formateur.

13 Os conselheiros principais da educação participam das atividades educativas em escolas do segundo grau (collèges e lycées), sem, no entanto, assumirem o trabalho docente em sala de aula. Assim como os professores, são selecionados por concurso nacional.

14 A academia é a circunscrição administrativa da educação nacional francesa. Cada uma das 30 academias francesas é dirigida por um reitor, que, nomeado pelo Presidente da República, deve definir a organização dos serviços da educação nacional no âmbito da academia que dirige.

15 O collège, primeiro segmento do nível secundário na educação francesa, atende os alu- 
nos egressos das écoles elementaires. É comporto por três ciclos, com duração total de quatro anos. O lycée (de estudos gerais e tecnológicos ou de formação profissional) oferece os três anos finais do nível secundário na França. Na organização educacional brasileira, essas etapas da escolarização correspondem, respectivamente, aos anos finais do ensino fundamental $\left(6^{\circ}\right.$ ao $9^{\circ}$ anos) e ao nível médio.

16 Concours de recrutement de professeurs des écoles, Concours de Recrutement de conseillers principaux d'éducation, Certificat d'aptitude au professorat de l'enseignement du second degré, Certificat d'aptitude au professorat de l'enseignement technique, Certificat d'aptitude au professorat de Lycée professionnel.

17 Maîtres d'accueil temporaires, professores dos anos iniciais que, em função do número insuficiente de maîtres formateurs, são indicados pela inspeção acadêmica para acolherem estagiários e professores iniciantes em suas classes. No entanto, os MAT, como são chamados, não assumem um estatuto de formador de novos professores.

18 Professores do segundo grau (colégio e liceu), titulares do Certificat d'aptitude à l'enseignement du second degré, especialistas no ensino de disciplinas específicas.

19 Professores especialistas no ensino de disciplinas específicas que obtiveram sucesso na "agregação", tradicional concurso que lhes permite lecionar nos colégios, nos liceus, mas também nas classes preparatórias às Grandes Escolas e no Ensino Técnico Superior. 20 Esse contexto foi alterado com a criação das já referidas ESPE. Cada ESPE está sob a responsabilidade administrativa de uma universidade e oferece o mestrado "Métiers de l'Enseignement, de l'Éducation et de la Formation" (MEEF), por meio de um consórcio formado pelas diversas universidades da mesma academia.

21 O ano letivo francês tem início em setembro e é finalizado em junho do ano subsequente.

22 Tendência que segue fortalecida com a criação das ESPE.

23 Validation des acquis personnels et professionnels.

24 Além da formação voltada para profissionais da área educacional, a instituição oferecia também formação na área de hotelaria e gastronomia.

25 Métier de l'éducation et de l'enseignement du $1^{\circ}$ degrée.

26 Enseigner en école maternelle et élémentaire e Concevoir des projets éducatifs et culturels en partenariat.

27 Carga horária mínima do curso, que poderia chegar a 566 horas em função do número de horas realizadas nos estágios supervisionados.

28 Os nomes dos informantes da pesquisa foram aqui substituídos por pseudônimos.

29 Marianne refere-se aos professores estagiários, recém-concursados e que são acompanhados e avaliados durante seu primeiro ano de atuação profissional.

30 O que permanece com as ESPE. 


\section{REFERÊNCIAS}

ALTET, M. As competências do professor profissional: entre conhecimentos, esquemas de ação e adaptação, saber analisar. In: PAQUAY; PERRENOUD; ALTET; CHARLIER (Orgs.). Formando professores profissionais. Quais estratégias? Quais competências? 2ed. Porto Alegre: Artmed, 2001. p.23-35.

BANCEL, D. Créer une nouvelle dynamique de la formation des maîtres. Paris: MEN, 1989. Rapport du recteur Daniel BANCEL à Lionel JOSPIN, ministre d'Etat, ministre de l'Education Nationale, de la Jeunesse et des Sports.

BARRÈRE, A.; LEGRAND, G. Éditorial. La formation professionnelle universitaire des enseignements. Recherche et formation, Paris, n.60, p.5-11, 2009.

BOURDIEU, P. Les trois états du capital culturel. Actes de la recherche en sciences sociales, Paris, n.30, p.3-6, nov. 1979.

BOURDIEU, P. Algumas propriedades dos campos. In: Questões de Sociologia. Rio de Janeiro: Ed. Marco Zero, 1983. p.89-94.

BOURDIEU, P. Raz̃oes práticas: sobre a teoria da ação. 7ed. Campinas: Papirus, 2005.

BOURDONCLE, R. De l'instituteur à l'expert. Les IUFM et l'évolution des institutions de formation. Recherche et formation, Paris, n.8, p.57-72, 1990.

BOURDONCLE, R. Professionnalisation, formes et dispositifs. Recherche et formation, Paris, n.35, p.117-132, 2000.

BOURDONCLE, R. Universitarisation. Recherche et formation, Paris, n.54, p.135-49, 2007. BOURDONCLE, R. L'universitarisation: structures, programmes et acteurs. In: ETIENNE, R.; ALTET, M. L.; PASQUAY, C.; PERRENOUD, L. P. L'université peut-elle vraimment former les enseignants? Bruxelas: De Boeck, 2009. p.19-28.

BRASIL. Ministério da Educação e Cultura. Secretaria da Educação Fundamental. Referenciais para a formação de professores. Brasília, 2002.

CHARTIER, A.-M. A questão da língua materna na formação continuada entre os anos 1970 e 2010 na França. In: FERREIRA, A. T. B.; SILVA, S. P. da Formação continuada de professores: reflexões sobre a prática. Pernambuco: Ed. Univ. da UFPE, 2010.

DE CERTEAU, M. A invenção do cotidiano: artes do fazer. 6.ed. Petrópolis: Vozes, 1994.

FRANÇA. Loi d'orientation sur l'éducation. Lei n 89-486, de 10 julho de 1989.

FRANÇA. Loi n ${ }^{\circ}$ 2005-380, d'orientation et de programme, de 23 de abril de 2005.

FRANÇA. Loi n 2007-1199, de 10 de agosto de 2007.

FRANÇA. Ministère de l'Education Nationale. Bulletin Officiel no 29, de 22 de julho de 2010. HOLMES GROUP. Tomorrow's schools of education. East Lansing, MI: Holmes Group, 1995.

LANG, V. La professionnalisation des enseignants. Paris: PUF,1999.

PELPEL, P. Les formateurs du terrain. Crise d'indentité et évolution du modéle de formation. Recherche et formation, Paris, n.22, p.65-80, 1996.

PELPEL, P. Accueillir, accompagner, former des enseignant: guide de réflexion et d'action. Lyon: Chornique Sociale, 2003.

PERRENOUD, P. O trabalho sobre o babitus na formação de professores: análise das práticas e tomada de consciência. In: PAQUAY; PERRENOUD; ALTET; CHARLIER Orgs.). Formando professores profissionais. Quais estratégias? Quais competências? 2ed. Porto Alegre: Artmed, 2001. p.161-184. 
MALET, R. Présentation. Former sous influence internationale: circulation, emprunts et transferts dans l'espace francophone. Recherche et formation, Paris, n.65, p.9-15, 2010.

MAUÉS, O. C. Reformas internacionais da educação e formação de professores. Cadernos de Pesquisa, São Paulo, n.118, p.89-118, 2003.

RIA, L.; LEBLANC, S.; SERRES, G.; DURAND, M. Recherche et formation en "analyse de pratiques": um exemple d'articulation. Recherche et formation, Paris, n.51, p.43-56, 2006.

RELATÓRIO Bancel, 1989. Créer une nouvelle dynamique de la formation des maîtres. Paris: MEN, 1989. Rapport du recteur Daniel BANCEL à Lionel JOSPIN, ministre d'Etat, ministre de l'Education Nationale, de la Jeunesse et des Sports.

ROQUET, P. L'emergence de l'accompagnement. Une nouvelle dimension de la formation. Recherche et formation, Paris, n.62, p.13-24, 2009.

SARTI, F. M. Leitura profissional docente em tempos de universitarização do magistério das séries iniciais. Tese (Doutorado em Educação) - Faculdade de Educação, Universidade de São Paulo, São Paulo, 2005.

SARTI, F. M.; BUENO, B. O. Leituras profissionais docentes e apropriação de saberes acadêmico-educacionais. Cadernos de Pesquisa, São Paulo, v.37, n.131, p.455-479, 2007.

SARTI, F. M. O triângulo da formação docente: seus jogadores e configurações. Educação e Pesquisa, v.38, n.2, p.323-338, 2012.

SOREL, M. Préambule. In: SOREL, M.; WITTORSKI, R. (Orgs.) La professionnalisation en actes et en questions. Paris: L'Harmattan, 2005. p.7-10.

SOUZA, D.T. R. de; SARTI, F. M. Mercado de formação docente: origens, dispositivos e consumidores. In: ENCONTRO DE PESQUISA EM EDUCAÇÃO DA REGLÃO SUDESTE (ANPED- Sudeste), 9., 2009, São Carlos. Anais... São Carlos: UFSCAR, 2009. CD-ROM, v.1, p.1-13.

Recebido em: 12/06/2013

Aprovado em: 08/11/2013

Contato:

Universidade Estadual Paulista (UNESP)

Departamento de Educação

Avenida 24 - A - 1515

CEP $13506-900$

Rio Claro | SP | Brasil 